\title{
Neglected and Underutilized Fruit Species in Sri Lanka: Prioritisation and Understanding the Potential Distribution under Climate Change
}

\author{
Sujith S. Ratnayake ${ }^{1,2, *(D)}$, Lalit Kumar ${ }^{2}$ and Champika S. Kariyawasam ${ }^{2}$ (1) \\ 1 Climate Change Secretariat, Ministry of Mahaweli Development and Environment, \\ Colombo 10120, Sri Lanka \\ 2 Ecosystem Management, School of Environmental and Rural Science, University of New England, Armidale, \\ NSW 2351, Australia; lkumar@une.edu.au (L.K.); ckariyaw@myune.edu.au (C.S.K.) \\ * Correspondence: gefsecsrilanka@gmail.com; Tel.: +61-266-773-5239
}

Received: 27 November 2019; Accepted: 19 December 2019; Published: 25 December 2019

\begin{abstract}
Neglected and underutilized fruit species (NUFS) can make an important contribution to the economy, food security and nutrition requirement for Sri Lanka. Identifying suitable areas for cultivation of NUFS is of paramount importance to deal with impending climate change issues. Nevertheless, limited studies have been carried out to assess the impact of climate change on the potential distribution of NUFS. Therefore, we examined the potential range changes of NUFS in a tropical climate using a case study from Sri Lanka. We prioritized and modeled the potentially suitable areas for four NUFS, namely Aegle marmelos, Annona muricata, Limonia acidissima and Tamarindus indica under current and projected climates (RCP 4.5 and RCP 8.5) for 2050 and 2070 using the maximum entropy (Maxent) species distribution modeling (SDM) approach. Potentially suitable areas for NUFS are predicted to decrease in the future under both scenarios. Out of the four NUFS, T. indica appears to be at the highest risk due to reduction in potential areas that are suitable for its growth under both emissions scenarios. The predicted suitable area reductions of this species for 2050 and 2070 are estimated as $>75 \%$ compared to the current climate. A region of potentially higher climatic suitability was found around mid-county for multiple NUFS, which is also predicted to decrease under projected climate change. Further, the study identified high-potential agro-ecological regions (AERs) located in the mid-country's wet and intermediate zones as the most suitable areas for promoting the cultivation of NUFS. The findings show the potential for incorporating predictive modeling into the management of NUFS under projected climate change. This study highlights the requirements of climate change adaptation strategies and focused research that can increase the resilience of NUFS to future changes in climate.
\end{abstract}

Keywords: climate change scenarios; climate suitability; fruit selection index; Maxent; species distribution modeling

\section{Introduction}

Sri Lanka is predominantly an agrarian-based country with world-renowned unique agricultural diversity [1]. Though the climate is generally tropical, differences can be observed across the country due to changes in rainfall and elevation [2]. Sri Lanka is divided into three distinct climatic zones primarily based on the annual rainfall: a wet zone $(2500-5000 \mathrm{~mm})$, a dry zone $(1250-1900 \mathrm{~mm})$ and an intermediate zone (1900-2500 mm) [3]. The island has been defined into 46 unique agro-ecological regions (AERs) (Figure S1) based on features such as rainfall, elevation, soil type, landform, land use and relief [4]. Sri Lanka is enriched with high biodiversity despite its small size of $65,610 \mathrm{~km}^{2}$ [2]. 
The variety of fruit species that are cultivated in different AERs is an important component of this biodiversity. This is evident by the over 237 recorded fruit species representing 56 plant families [5]. There are more than 60 varieties of underutilized fruit crops in Sri Lanka that are grown particularly in marginal environments [6]. These fruits are generally known as neglected and underutilized fruit species (NUFS) with under-exploited potentials for contributing to improving livelihoods (i.e., food security, income generation and health) and ecosystem stability $[7,8]$. Underutilized is generally used to refer to species whose potential has not been fully realized and exploited. In the Sri Lankan context, NUFS are still significant for local food and nutrition security and traditional medicine. Some species are widely distributed globally but may occupy locally confined niches [9]. Considering the current demand for NUFS due to health benefits and socio-cultural use, future research should be focused on the characterization and genetic conservation of NUFS $[9,10]$. These plants possess rich genetic diversity with unprecedented potential to improve the quality and resilience of future crops, and can be used by plant breeders for future crop improvements [11,12]. NUFS have received little consideration or have been completely ignored by agricultural researchers, plant breeders, policymakers, extension workers and farmers, although some research work has been carried out for collection characterization and evaluation of these species $[13,14]$. Increasing global population and varying dietary requirements are likely to put pressure on food and agriculture in the future [15]. Thus, more diversified agricultural and food systems are needed to cater these growing demands [13]. Recent studies show that NUFS have very good potential to address the food, nutrition and income security of rural peoples living in drought-prone areas [16]. Thus, promoting these NUFS to make them more "consumer-friendly" and "commercial" can be considered a powerful means of achieving sustainable development goal 2 (SDG 2) (i.e., reduction of poverty and malnutrition). They have the potential to enhance the diversity of food systems and, further, to make agricultural production systems less vulnerable to climate change, as these plants are hardy and resilient to such changes [13,17-19]. They can thrive in harsh climatic conditions and nutrient-poor degraded habitats [20]. As such, these species have been increasingly recognized for the future adaptation of food production to climate change [8].

The selected four NUFS—Limonia acidissima L., Aegle marmelos (L.) Correa, Annona muricata L. and Tamarindus indica L.- -are terrestrial trees that are widely distributed in tropical regions including the Indian subcontinent [21-24]. All four species are mainly propagated by seeds [14,25]. They have tremendous potential for medicinal purposes and as food resources. Generally, all parts of these plants (i.e., leaf, bark, fruit, seed and root) have ethnomedicinal importance and are widely used in traditional medicine to treat various illnesses [21,24,26,27]. For instance, L. acidissima contains various pharmacological properties such as hepatoprotective, anti-diabetic, anti-tumor, anti-ulcerative, wound-healing and anti-microbial activities, and is used to cure asthma, tumors, cardiac debility, hepatitis and wounds $[24,28,29]$. A. marmelos possesses antiviral, antifertility, radioprotective, anticancer, chemopreventive, antidiarrheal, ulcer healing, diuretic, antigenotoxic, antimicrobial, radioprotective, antipyretic and anti-inflammatory properties and thus it is a remedy for a range of diseases [30]. A. muricata is used for curing hypertension, headaches, fever, rheumatism, diabetes, insomnia, parasite infection, diarrhea, dysentery and many more conditions [26,31]. Extract of A. muricata leaves is used as an alternative therapy for cancer as it causes apoptosis of the liver cancer cells [32]. Likewise, T. indica is used for abdominal pain, wound healing, constipation, inflammation, respiratory problems, diarrhea and dysentery $[25,27,33]$.

Temperature and rainfall in the South Asian region are projected to increase significantly by 2100 under climate change [34]. Multi-model ensemble prediction carried out by the Department of Meteorology Sri Lanka indicates that the negative rainfall anomaly, especially in the dry zone of Sri Lanka, can be expected in both medium emissions (RCP 4.5) and high emissions (RCP 8.5) scenarios for 2050 and 2070. Further, multi-model ensemble prediction indicates an increasing trend of the minimum and maximum temperatures for 2050 and 2070 [35]. As Sri Lanka is an island highly vulnerable to extreme climatic events, the potential consequences of climate change that can impact the distribution of species could be significant [36]. Potential reduction of rainfall and increase of temperature in 
the dry zone may increase vulnerability of low country dry zone ecosystems. Such adverse changes can reduce agricultural productivity and leave farming households struggling for their livelihoods. Further, climate changes in the future may potentially impact pollinator species, which could have an additional constraint on potential area suitability of NUFS, as wild plants are greatly dependent on pollinators for fruit production [37].

In Sri Lanka, priority setting has not been carried out systematically to improve conservation and sustainable use of NUFS [3]. More specifically, the environmental factors that influence or limit distribution of these species have not been investigated. Understanding the current and potential distribution of NUFS is essential to meeting the future challenges of global food security [10]. However, there has been no comprehensive study undertaken with the purview of examining the potential distribution of these NUFS under climate change. We modeled the distribution of four NUFS in Sri Lanka under current and future (RCP 4.5 and RCP 8.5) climates for 2050 and 2070. The objectives of this study were to (i) prioritize NUFS in Sri Lanka to be considered into national food and nutrition security programs; (ii) model potential distribution of four priority NUFS and calculate range changes under projected climate change and (iii) define areas that potentially support multiple NUFS in the current climate and in scenarios of global warming. Our study is significant as it is the first study of this kind in Sri Lanka to use species distribution modeling (SDM) concepts to identify the potential distribution of NUFS under projected climate change. This information can be used for identifying future climate-suitable areas for promoting the cultivation of NUFS.

\section{Materials and Methods}

\subsection{Priority Neglected and Underutilized Fruit Species (NUFS) Selection}

Williams and Haq [38] developed a set of criteria consisting of statements for selecting priority crops from a particular geographical region. In an expert consultation meeting held on 20 December 2017 at the Plant Genetic Resources Centre, 40 experts from relevant agencies (Government Departments and research stations, academia, non-governmental organizations and leaders of community-based organizations) discussed and reviewed the above criteria. These criteria were modified and developed from 26 statements as per the study purpose and country context (Table 1 ). To calculate the Fruit Selection Index (FSI), we used the following formula adapted from Jayasinghe-Mudalige and Henson [39].

$$
\mathrm{FSI}=\sum_{\mathrm{a}=1}^{\mathrm{s}} \mathrm{a}_{i s} . \mathrm{Us} / \mathrm{aU}
$$

$\mathrm{U}$ is a set of statements $\left(\mathrm{U}=\mathrm{U}_{1}, \mathrm{U}_{2}, \ldots, \mathrm{U}_{s}\right)$ that explains different factors to be considered for prioritizing NUFS in this study. The group of experts (i) provided an integer score (a) for each statement (e.g., $a_{i 1}, a_{i 2}, \ldots, a_{i s}$ on $U_{1}, U_{2}, \ldots, U_{s}$, respectively). Each statement was marked as "YES" or "NO" for each NUFS by considering the availability of factors in each given statement. If the statement was marked as "YES", a score was given based on degree of importance: high $(\mathrm{H})=3$, moderate $(\mathrm{M})=2$ and low $(\mathrm{L})=1$. The maximum score that could be obtained by any statement for any NUFS was 3. This score was multiplied by the number of statements given in a category to get the maximum potential score $(\mathrm{aU})$. Sum of the scores provided by statements in a category was divided by the maximum potential score of that category to obtain the index value for this category. The total of seven index values was divided by the number of categories (seven) to get the FSI (Table S1). The prioritized four NUFS were considered for further analysis through SDM. 
Table 1. Twenty-six statement criteria used to prioritize neglected and underutilized fruit species (NUFS) in Sri Lanka.

\begin{tabular}{|c|c|c|c|}
\hline Category No. & Category Name & Statement No. & Statement \\
\hline \multirow[t]{2}{*}{1} & \multirow{2}{*}{$\begin{array}{l}\text { Research and policy } \\
\text { framework }\end{array}$} & $\mathrm{U}_{1}$ & $\begin{array}{l}\text { Importance of national food production and food } \\
\text { security programs }\end{array}$ \\
\hline & & $\mathrm{U}_{2}$ & $\begin{array}{c}\text { Importance of national and regional agriculture } \\
\text { research system }\end{array}$ \\
\hline \multirow{4}{*}{2} & \multirow{4}{*}{$\begin{array}{l}\text { Germplasm and } \\
\text { agro-ecology }\end{array}$} & $\mathrm{U}_{3}$ & Availability of germplasm \\
\hline & & $\mathrm{U}_{4}$ & Current genetic conservation status \\
\hline & & $\mathrm{U}_{5}$ & Potential demand for germplasm \\
\hline & & $\mathrm{U}_{6}$ & Adaptation to local climate and soil \\
\hline \multirow{2}{*}{3} & \multirow{2}{*}{ Acceptability } & $\mathrm{U}_{7}$ & Local preferences/consumption \\
\hline & & $\mathrm{U}_{8}$ & Rural income generation \\
\hline \multirow{4}{*}{4} & \multirow{4}{*}{ Uses } & $\mathrm{U}_{9}$ & Nutritional value and health benefits \\
\hline & & $\mathrm{U}_{10}$ & Cultural acceptance and consumer preferences \\
\hline & & $\mathrm{U}_{11}$ & Potential diversification for products \\
\hline & & $\mathrm{U}_{12}$ & Multiple uses (wood value, medicinal value, etc.) \\
\hline \multirow{8}{*}{5} & \multirow{8}{*}{ Production and practices } & $\mathrm{U}_{13}$ & Wide adaptability \\
\hline & & $\mathrm{U}_{14}$ & Cropping systems suitability \\
\hline & & $\mathrm{U}_{15}$ & Satisfies need for crop diversification \\
\hline & & $\mathrm{U}_{16}$ & Pest/disease situation \\
\hline & & $\mathrm{U}_{17}$ & Production and technology \\
\hline & & $\mathrm{U}_{18}$ & Seasonality \\
\hline & & $\mathrm{U}_{19}$ & Availability of planting material \\
\hline & & $\mathrm{U}_{20}$ & Local Knowledge \\
\hline \multirow{3}{*}{6} & \multirow{3}{*}{ Post-harvest } & $\mathrm{U}_{21}$ & Possibility of storage \\
\hline & & $\mathrm{U}_{22}$ & Processing technology \\
\hline & & $\mathrm{U}_{23}$ & Products in relation to markets \\
\hline \multirow{3}{*}{7} & \multirow{3}{*}{ Market and value chain } & $\mathrm{U}_{24}$ & Access to market \\
\hline & & $\mathrm{U}_{25}$ & Potential value addition \\
\hline & & $\mathrm{U}_{26}$ & Potential export processing \\
\hline
\end{tabular}

\subsection{Species Occurrence Data}

For this study, 781 occurrence records of four prioritized NUFS were extracted from a database developed as a result of field exploration and stakeholder consultation surveys conducted in four major donor-funded projects implemented by the Department of Agriculture and the Ministry of Environment, Sri Lanka during 2003-2018 (see Table S2 for details). During field and stakeholder surveys of these projects, geo-referenced NUFS occurrence data had been recorded from various sources, research and development institutes of the Department of Agriculture, national herbarium, experts and community consultations. Figure 1 shows the distribution of occurrences of four NUFS that were used for the study.

Spatial sampling bias is an issue in predictive modeling that causes spatial autocorrelation, resulting in poor model performance [40]. In order to reduce the effects of spatial sampling bias, occurrences were filtered in ArcMap using one of the predictor variables, enabling each grid cell to have only one occurrence record in the geographic areas where the study species are distributed (Table S3). To address the effect of sampling bias in species and background data, we used bias files by constraining the background data to have the same bias as the occurrence data [41]. In this case, we limited background point selections to the districts where NUFS occurrence data were distributed. 
This provided Maxent a background file with a similar bias to the sample data in order to fine tune the Maxent models [42].



Figure 1. Distribution of occurrence records for selected priority NUFS (Limonia acidissima, Aegle marmelos, Annona muricata and Tamarindus indica) in different climatic zones of Sri Lanka.

\subsection{Environmental Variables}

We downloaded 19 bioclimatic variables with a spatial resolution of 30 arc-seconds $\left(\sim 1 \mathrm{~km}^{2}\right)$ from the Worldclim website for current (representative of 1960-1990) and future climates (http: //www.worldclim.org/) [43]. We used the MIROC5 atmosphere-ocean general circulation model (GCM) to make future projections under medium emissions (RCP 4.5) and high emissions (RCP 8.5) scenarios for 2050 and 2070. MIROC5 has been tested by previous empirical studies for its efficiency of climate 
change simulations, particularly for South Asia [44-47], and, furthermore, broadly used in recent SDM studies in that region [48-51]. Multicollinearity testing was conducted to remove highly correlated variables. We used the "removeCollinearity" function of the Package "virtualspecies" (version 1.4-4) in $\mathrm{R}$ to remove correlated variables [52]. This method of variable selection has recently been used in SDM literature [48]. The analysis resulted in seven groups of intercorrelated variables at Pearson's correlation coefficients $(r) \geq 0.7$ (Figure S2). While selecting variables from groups of intercorrelated variables, we were careful to pick ecologically meaningful predictors that reasonably respond to climate change and species distribution. The selected bioclimatic variables contained tolerance limits of temperature and precipitation that impose constraints on their distribution. Thus, seven nonredundant bioclimatic variables with relevance to NUFS distribution were chosen for their potential significance based on our knowledge and published literature [53-55]. The variables selected included mean diurnal range (BIO2), maximum temperature of the warmest month (BIO5), minimum temperature of the coldest month (BIO6), annual precipitation (BIO12), precipitation of driest month (BIO14), precipitation seasonality (BIO15) and precipitation of coldest quarter (BIO19). The importance of the contribution of ecologically meaningful non-climatic variables has been frequently discussed in predictive modeling literature [56,57]. We enriched the chosen bioclimatic data with selected ecophysiologically meaningful non-climatic variables: elevation (dem), aspect (direction of slope), soil and land cover. Ecophysiologically significant non-climatic variables increase the predictive power of species distribution models of plants; thus, failure to include these potentially important variables in models can result in inaccurate predictions restraining predictive capacity [58]. These variables are key determinants of plant distribution, and the importance of soil variables has been particularly identified for distribution of fruit species [59]. We downloaded global land cover data at a 300-m spatial resolution from the European Space Agency GlobCover Portal (http://due.esrin.esa.int/page_globcover.php). We received elevation, aspect and soil data used by Kadupitiya, et al. [60]. We resampled those high-resolution raster layers and changed the resolution same as with bioclim layers $\left(\sim 1 \mathrm{~km}^{2}\right)$ by providing the same parameters using ArcGIS toolbox. Therefore, we had 11 identical variables altogether of the same resolution, projection and extent for modeling the four priority NUFS in Sri Lanka.

\subsection{Maxent Modeling}

Maximum Entropy Species Distribution Modeling (Maxent) software version 3.4.1 was employed for the study [61]. Maxent is based on the maximum entropy principle-in other words, the most spread out or closest to uniform distributions [62]. We selected the Maxent modeling technique for several reasons: (i) Maxent is relatively more robust and frequently outperforms many other well-established presence-only modeling algorithms [63-67]; (ii) Maxent is less influenced by spatial errors in sample data and performs well with geographically biased occurrence data [68,69]; and (iii) Maxent generates a continuous model output of relative probability of presence, allowing fine distinctions in binary predictions [62-64]. Further, Maxent is widely used in SDM literature for various applications, particularly to identify potential areas of suitability [66]. We selected "do jackknife to measure variable importance", "create response curves", "make pictures of predictions" and "write background prediction". Logistic output was selected for easy interpretation of the outcome [70,71]. In the logistic output, the relative probability of presence is illustrated by a linear scale of values from 0 to 1 , where 0.5 represents typical presence localities (see Phillips [72] for details). We selected cross-validation with 10 replicates, where occurrences are divided into 10 equal-size parts and all occurrences are used for model validation to efficiently generate a more accurate result $[67,72]$. Auto features were used as recommended ( $>80$ training samples) except in the A. muricata model, where we used linear, quadratic and hinge features due to limited training samples [73]. We increased the number of iterations to 1000, enabling the algorithm to get close to convergence for smooth prediction [62] while the other parameters were kept at default. Default values are set in Maxent based on performance across a wide range of taxa to receive an optimum model output and hence recommended to use when 
several models are run simultaneously [71]. Models were run individually for four prioritized NUFS with the selected subsets of variables under current and future climate changes.

\subsection{Model Performance}

In SDM literature, model robustness is frequently verified using discrimination metrics such as the threshold independent area under the receiver operating characteristic curve (AUC) criterion and the threshold dependent true skill statistic (TSS) [62,74]. Therefore, the accuracy of prediction of selected NUFS was primarily assessed by the AUC and TSS. However, both these measures have criticisms due to their dependency on prevalence $[52,74]$. Therefore, relative satisfactory performance in both measures was considered while selecting models. The AUC ranged from 0 to 1 while the TSS ranged from -1 to +1 . Upper levels of both measures signify the perfect prediction of presences and absences [41,74]. In general, an AUC value of $<0.7$ indicates poor performance; a value of $0.7-0.9$ indicates moderate performance; and a value $>0.9$ indicates high performance $[75,76]$. Similarly, TSS values that are $<0.4$ are considered poor, $0.4-0.8$ moderate and $>0.8$ very good [77]. Additionally, we tested the relative performance of models using two alternative metrics: sensitivity and specificity.

\subsection{Potential Area of Prediction}

The Maxent generated model output, which is an average output of the replicated runs [72], was imported into ArcMap (ArcGIS version 10.4.1) for suitability analysis. Maximizing the sum of the sensitivity and specificity logistic threshold was used to discriminate presences and absences, as this approach is suggested for models that use presence-only and background data (i.e., Maxent) [78]. The suitable area distribution was visualized for each NUFS under current climates and under two emissions scenarios for 2050 and 2070. The "reclassify" tool of ArcGIS was used to visualize binary presence-absence maps showing areas above the threshold as suitable and areas below the threshold as not suitable for potential spread of species. In each case, the potentially suitable area of spread was calculated in $\mathrm{km}^{2}$ using the ArcMap tool field calculator.

A combined raster was generated by merging four classified layers using the spatial analyst toolbox of ArcMap. We received five climatic suitability classes as very low (0 NUFS), low (1 NUFS), moderate (2 NUFS), high (3 NUFS) and very high (4 NUFS). The very high class represented the highest number of NUFS that overlapped in a given place, whereas the very low category represented the areas not suitable for any of the given NUFS. The suitability maps were developed for future climatic scenarios as well. The classes used for classifying the combined raster were uniform among all maps. Thus, five combined maps of climatic suitability were developed under current and future climatic scenarios.

\section{Results}

The value of the FSI ranged from $0-1$, indicating that the NUFS with the highest value was the best fruit to be selected. Table 2 shows 30 NUFS grown in Sri Lanka based on the scores generated by the FSI. Accordingly, L. acidissima L. (Rutaceae) ranked the highest followed by A. marmelos L. (Rutaceae), A. muricata L. (Annonaceae), Phyllanthus emblica L. (Phyllanthaceae) and T. indica L. (Fabaceae). Evaluation of the performance of NUFS models was found to be acceptable for L. acidissima, A. marmelos, A. muricata, and T. indica to analyze the impact of climate change on potential distribution (Table S2). The performance of the P. emblica model was found to be not satisfactory and thus eliminated. 
Table 2. Priority setting of 30 NUFS of Sri Lanka based on the results of the fruit selection index (FSI).

\begin{tabular}{|c|c|c|c|c|c|}
\hline Rank & Scientific Name & Family & Common Name & Local Name & FSI \\
\hline 1 & Limonia acidissima & Rutaceae & Wood apple & Divul & 0.696 \\
\hline 2 & Aegle marmelos & Rutaceae & Bael, bhel & Beli & 0.674 \\
\hline 3 & Annona muricata & Annonaceae & Soursop & Katuannoda & 0.648 \\
\hline 4 & Phyllanthus emblica & Phyllanthaceae & Indian gooseberry & Nelli & 0.629 \\
\hline 5 & Tamarindus indica & Fabaceae & Tamarind & Siyambala & 0.595 \\
\hline 6 & Citrus reticulata & Rutaceae & Mandarine & Dodam & 0.564 \\
\hline 7 & Psidium guajava & Myrtaceae & Guava & Pera & 0.535 \\
\hline 8 & Syzygium aqueum & Myrtaceae & Water apple & Jambu & 0.438 \\
\hline 9 & Garcinia quaesita & Clusiaceae & Brindle berry & Goraka & 0.403 \\
\hline 10 & Dialium ovoideum & Fabaceae & Velvet tamarind & Gal siyambala & 0.401 \\
\hline 11 & Mangifera indica. & Anacardiaceae & Mango & Mee amba & 0.399 \\
\hline 12 & Citrus grandis & Rutaceae & Pumello & Jambola & 0.399 \\
\hline 13 & Psidium catlleianum & Myrtaceae & Cherry guava & Cherry pera & 0.351 \\
\hline 14 & Flacourtia inermis & Salicaceae & Lovi/batoko plum & Lovi & 0.351 \\
\hline 15 & Pouteria campechiana & Sapotaceae & Canistel & Lavulu & 0.341 \\
\hline 16 & Elaeocarpus serratus & Elaeocarpaceae & Ceylon olive & Veralu & 0.337 \\
\hline 17 & Lansium domesticum & Meliaceae & Langsat & Gaduguda & 0.337 \\
\hline 18 & Flacourtia indica & Salicaceae & Ramontchi & Uguressa & 0.326 \\
\hline 19 & Manilkara zapota & Sapotaceae & Sapodilla & Sapodilla & 0.309 \\
\hline 20 & Ziziphus mauritiana & Rhamnaceae & Chinese date & Masan & 0.309 \\
\hline 21 & Averrhoa carambola & Oxalidaceae & Carambola & Kamaranga & 0.253 \\
\hline 22 & Psidium spp. & Myrtaceae & Guava & Jam pera & 0.233 \\
\hline 23 & Syzygium cumini & Myrtaceae & Black plum & Dan & 0.222 \\
\hline 24 & Cynometra cauliflora & Fabaceae & Nam nam & Nam nam & 0.201 \\
\hline 25 & Carissa spinarum & Apocynaceae & Conkerberry & Karamba & 0.201 \\
\hline 26 & Manilkara haxandra & Sapotaceae & Ceylon iron wood & Palu & 0.191 \\
\hline 27 & Grewia tiliifolia & Tiliaceae & Dhaman & Damuna & 0.139 \\
\hline 28 & Euphoria longana & Malvaceae & Longan & Mora & 0.128 \\
\hline 29 & Schleichera oleosa & Sapindaceae & Ceylon oak & Kon & 0.128 \\
\hline 30 & Drypetes sepiaria & Putranjivaceae & - & Weera & 0.128 \\
\hline
\end{tabular}

The analysis of variable contributions table of the Maxent model provides estimates of relative contributions of the environmental variables. Figure 2 shows the relative percentage contributions of the three highest contributing environmental variables to the Maxent models for four NUFS. The figure presented is a result of current climate modeling. However, under future climates, the same variables a show similar performance. Therefore, these are the major environmental variables that influence climatic suitability for the fruit species under present and future climates. Among the variables, soil contributed the most to the A. muricata and L. acidissima models, whereas precipitation of driest month (BIO14) and minimum temperature of the coldest month (BIO6) contributed the highest to A. marmelos and T. indica models, respectively. Overall, soil appeared to be an influencing environmental variable to the distribution pattern of all four species. The relative contribution of aspect variables to the model prediction was negligible. Jackknife testing also confirmed soil as the leading variable in predicting the potential distribution of $A$. muricata and L. acidissima. Precipitation seasonality (BIO15) and mean diurnal temperature range (BIO2) were the most contributing variables in A. marmelos and T. indica models, respectively. The aspect contribution was negligible in all four models (Figure S3). 




Figure 2. Relative importance (\%) of the highest contributing environmental variables in the current climate (maximum temperature of the warmest month (BIO5), minimum temperature of the coldest month (BIO6), precipitation of the driest month (BIO14) and precipitation of the coldest quarter (BIO19)) to the Maxent models of each of the selected priority NUFS in Sri Lanka: Limonia acidissima, Aegle marmelos, Annona muricata and Tamarindus indica.

Figure 3 shows the projected potential distribution maps for the four NUFS species under current climate and climate change scenarios. We visualized the potential areas of suitability for each NUFS above the selected threshold of maximum training sensitivity plus the specificity logistic threshold (Figure S4). Accordingly, the wet and intermediate climatic zones of Sri Lanka were predicted as highly suitable for A. marmelos distribution. The potentially suitable area of A. marmelos under the current climate was $10,621 \mathrm{~km}^{2}$ (Figure 4, Table S4) and the majority of this potentially suitable areas was located around Kandy, Kegalle, Colombo, Gampaha, Kalutara and Kurunegala districts (see Figure S5 for a district map). The potential area of the suitability of this NUFS is predicted to decrease in the future, particularly around the Kurunegala district. Under the current climate, the potentially suitable area for A. muricata was estimated to be $7579 \mathrm{~km}^{2}$, involving mainly the central parts of Sri Lanka representing the Kandy, Kurunegala, Matale and Kegalle districts as well as parts of the Matara and Ratnapura districts. Under the medium-emissions scenario, this suitable area is predicted to contract by 2050 and increase again by 2070 . Under the high-emissions scenario, the potentially suitable area of this NUFS is predicted to decrease (63\%) continuously until 2070. The potentially suitable area around the Kandy district is predicted to be relatively stable under climate change. In the current climate, the L. acidissima model predicted a potentially suitable area of $13,135 \mathrm{~km}^{2}$ mainly around the Anuradhapura, Kurunegala, Polonnaruwa and Vavunia districts. This potential area of suitability is predicted to increase by 2050 under the medium-emissions scenario; however, it is predicted to decrease again by 2070 . Under the high-emissions scenario, the potentially suitable area of L. acidissima is predicted to contract prominently $(72 \%)$ by 2070 , limiting this NUFS only to the Kurunegala district and a few adjacent areas. T. indica had the lowest potentially suitable area of $5173 \mathrm{~km}^{2}$ under the current climate, including predominantly Anuradhapura, Matale, and Badulla districts and some scattered areas adjacent to these districts. According to the projected maps of suitability, climate change is predicted to influence the potential distribution of this species in the future, resulting in dramatic area contraction. Under the medium-emissions scenario, the predicted suitable area reductions of $T$. indica for 2050 and 2070 were estimated as $78 \%$ and $94 \%$ compared to the current climate, whereas under the 
high-emissions scenario these figures were $82 \%$ and $89 \%$, respectively. By 2070 , the potential suitability of this NUFS is predicted to be mostly restricted to around the Kandy district and surrounding areas under both emissions scenarios. Overall, all four NUFS are predicted to decrease in the potential area of suitability under medium- and high-emissions scenarios in the future.

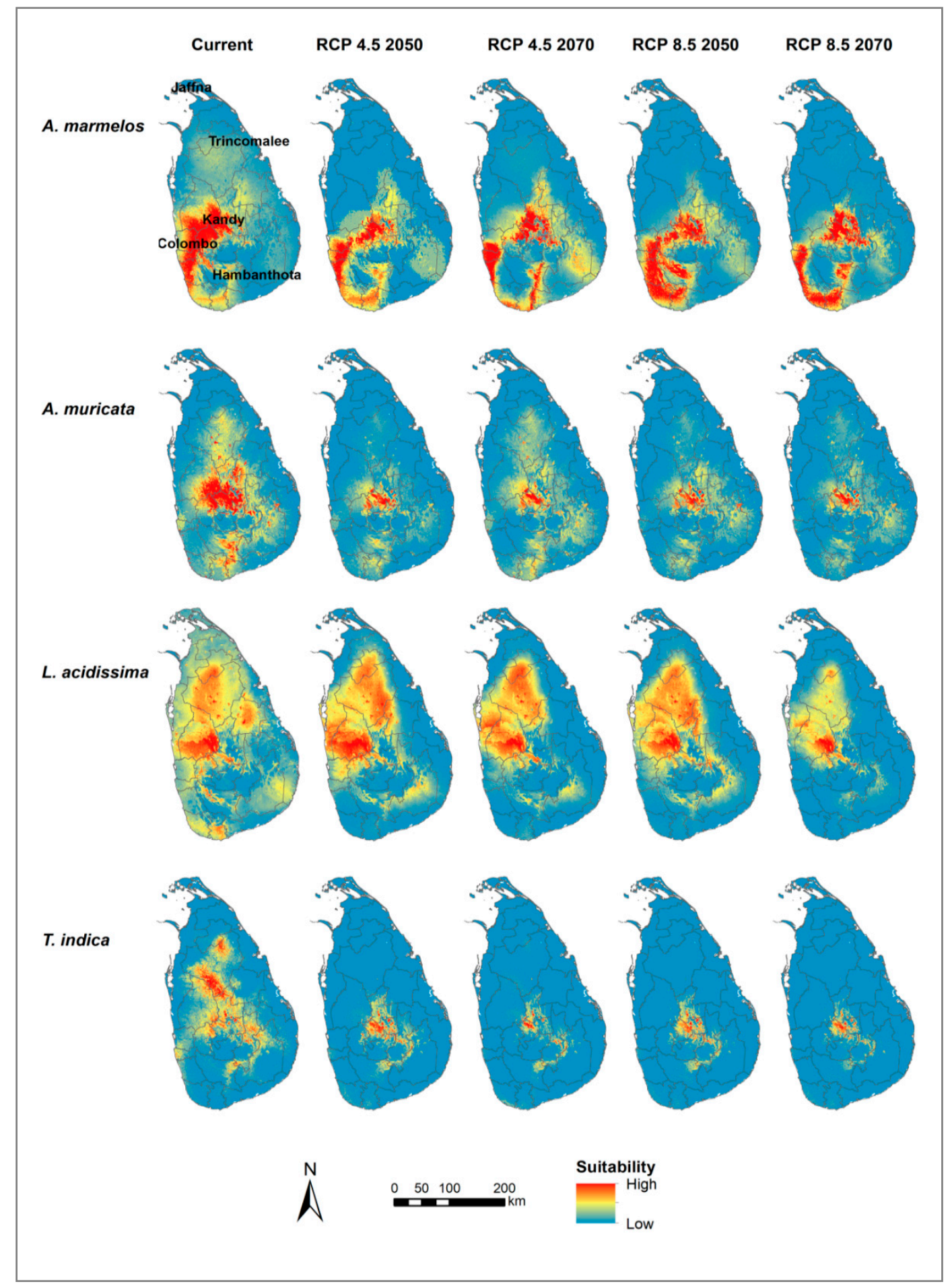

Figure 3. Projected potential distribution maps for the selected priority NUFS Limonia acidissima, Aegle marmelos, Annona muricata and Tamarindus indica in Sri Lanka under medium-emissions (RCP 4.5) and high-emissions (RCP 8.5) scenarios for 2050 and 2070. The map colors indicate 0 (blue) to 1 (red) probability of occurrence. 


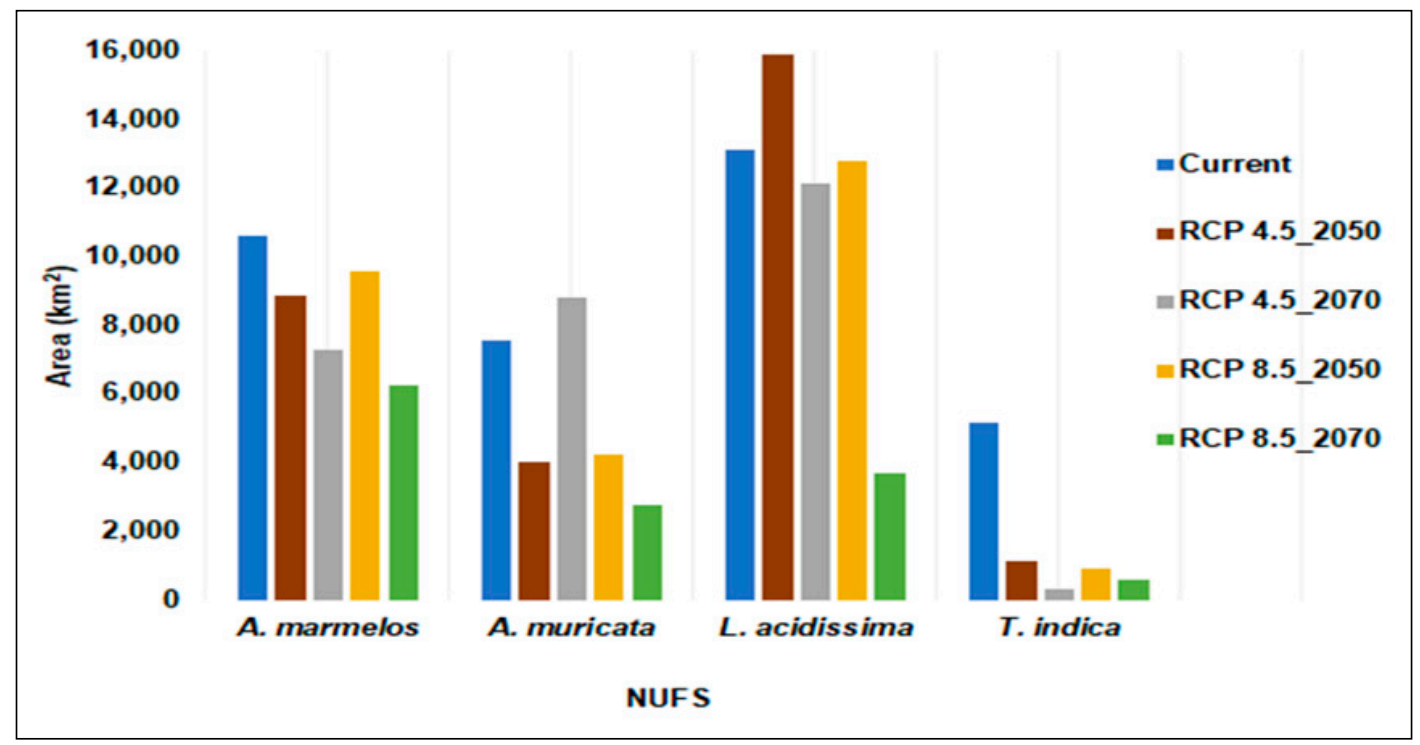

Figure 4. Projected suitable areas $\left(\mathrm{km}^{2}\right)$ of the selected priority NUFS Limonia acidissima, Aegle marmelos, Annona muricata and Tamarindus indica in Sri Lanka under the current climate, medium-emissions (RCP 4.5) and high-emissions (RCP 8.5) scenarios for 2050 and 2070.

The combined map of climatic suitability of four NUFS (Figure 5) under the current climate and future scenarios shows a region potentially suitable for the establishment of multiple NUFS. This area lies around the mid-county, particularly the area adjoining the Kurunegala, Kandy, Matale and Kegalle districts. This area is projected to reduce significantly and confine to around the Kandy district in the future under climate change. 


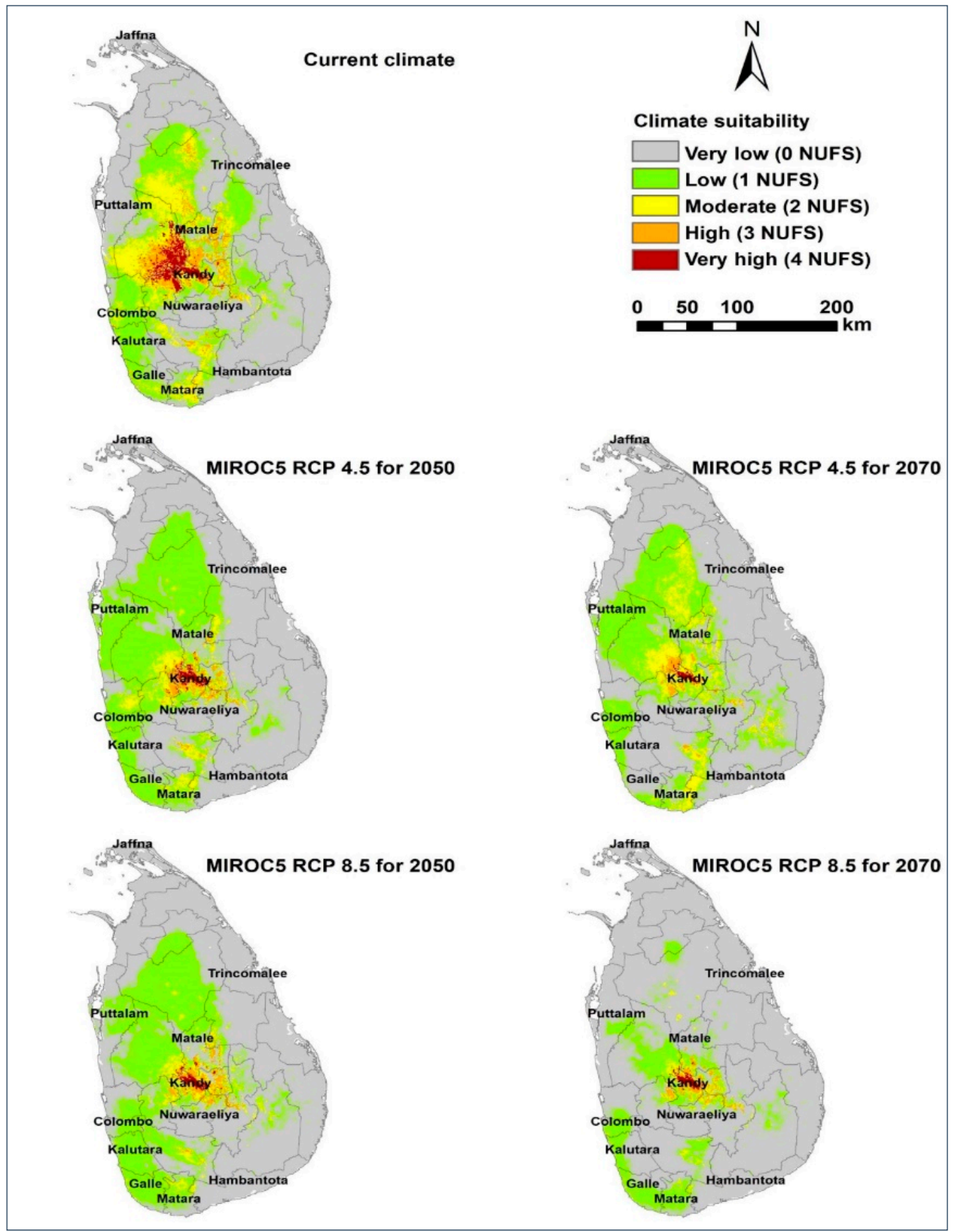

Figure 5. Projected climatic suitability for the establishment of multiple NUFS in Sri Lanka under the current climate, medium-emissions (RCP 4.5) and high-emissions (RCP 8.5) climatic scenarios for 2050 and 2070.

\section{Discussion}

Using a case study from Sri Lanka, we showed that the climatic suitability of NUFS will decrease in the future in tropical countries as a result of climate change. This may have implications on global food security, human nutrition and livelihood. The study provides important information about the habitat requirements of these NUFS for future prospecting. Both analysis of variable contribution and Jackknife testing of Maxent revealed that soil is an important environmental variable for determining 
the potential distribution of all four evaluated NUFS. We used soil as one of the variables to determine the likely areas that these NUFS can spread, but soil is not a factor that is impacted by climate. Among the other influencing environmental variables, precipitation of the driest month (BIO14), mean diurnal range (mean of monthly (max temp-min temp) (BIO2), minimum temperature of the coldest month (BIO6), precipitation seasonality (coefficient of variation) (BIO5), elevation (dem) and maximum temperature of the warmest month (BIO5) were significant.

A. muricata grows up to $1000 \mathrm{~m}$ elevation in areas with warm humid climates, with an average temperature of $18{ }^{\circ} \mathrm{C}$ and a rainfall greater than $1500 \mathrm{~mm}[23,79]$. The potentially suitable areas of A. muricata lie mainly in the central parts of Sri Lanka (in and around the Kandy district) as the prevailing climatic conditions in this area are ideal for its growth. Furthermore, the soil types prevailing around the Kandy district (i.e., reddish brown latosolic soils, red-yellow podsolic soils and immature brown loams) can be suitable for $A$. muricata cultivation. L. acidissima is reported to grow from coastal areas to an elevation of about $450 \mathrm{~m}$ in a range of soil conditions where the mean annual temperature is $30^{\circ} \mathrm{C}$ and mean annual rainfall is in the range $1250-1900 \mathrm{~mm}$ [14]. The model predicted a potentially suitable area for L. acidissima in the low country dry zone, which receives similar climatic conditions. L. acidissima is adapted to tolerate drought conditions, and thus is appropriate for the drier areas similar to conditions prevailing in the dry zone of Sri Lanka. This plant can grow well in reddish-brown earths and red-yellow podsolic soils prevailing in the dry zone. In Sri Lanka, A. marmelos is widely distributed in dry, intermediate and wet zones [14]. It grows well in well-drained soils up to $1200 \mathrm{~m}$ in elevation where the mean annual temperature range is from -6 to $48^{\circ} \mathrm{C}$ and mean annual rainfall is 570-2000 $\mathrm{mm}$ [80]. The model suggests that the potential area lies predominantly around the Kandy, Kegalle, Kurunegala, Gampaha and Kalutara districts in the current climate. Under future scenarios, the species is predicted to move southward and be confined to the wet zone areas, suggesting that the species will no longer tolerate the projected increased temperature. T. indica is a light-demanding tree that grows well in dry climates and needs an evenly distributed mean annual rainfall of 500-1500 mm as well as a maximum annual temperature ranging from 33 to $37^{\circ} \mathrm{C}$ with a minimum of 9.5 to $20^{\circ} \mathrm{C}$ [22]. The plant grows in a wide range of soils [14]. In the current climate, T. indica is predicted to be distributed around north-central and central parts of Sri Lanka. However, the potential distribution is predicted to contract, move inward and be restricted around central areas of the country in the future. The projected high-temperature increases in the dry and intermediate zones may potentially limit the distribution of this plant in those areas. Such information is useful for developing measures for conservation and sustainable utilization of NUFS in order to enhance their support to global food crises.

Our results imply that potentially suitable areas of all four NUFS are predicted to decrease by more than $40 \%$ by 2070 compared to the current climate under a high-emissions scenario (Figure 4 ). Out of the four NUFS, T. indica is predicted to be at the highest risk of suitable area reduction in terms of percentage area loss compared to the current climate, suggesting the requirement of immediate management concerns. Moreover, potentially suitable areas of all four NUFS are predicted to be confined to the relatively cooler high elevation areas (i.e., central highlands) of the country. Likewise, the projected maps of multiple species establishments show an area of potential NUFS concentration around the mid-country that is projected to decrease under climate change. NUFS are ecologically responsive to climate and thus their potential distribution is limited by their capacity to tolerate climatic changes [14]. Our findings show that NUFS grown in the low country's dry and intermediate zones are predicted to be at a relatively higher risk. The trend analysis conducted in Sri Lanka using long-term climate data has revealed a decreasing trend of the diurnal temperature range (i.e., the minimum temperature of the country is increasing faster than the maximum temperature) and the annual rainfall of the country, prominently in the dry zone [35]. Therefore, such projected temperature and rainfall changes mediates extreme climate conditions and can result in serious impacts on the potential distribution of NUFS, shifting and limiting their suitability to higher altitudes.

Spatial distribution of NUFS has a direct relationship with the agro-ecology of the country [10]. The number of potentially suitable AERs for these four NUFS under current climates is predicted to 
reduce in the future, and is even more prominent under the high-emissions scenario by 2070 (Table S5). This implies that the capacity of these NUFS to spread in a heterogeneous agro-ecological environment will be reduced in future. This study found that AERs located in the wet zone mid-country and intermediate zone mid-country are the most suitable areas for growing NUFS with the adverse impacts of future climate change. Therefore, other important factors that may affect the cultivation of these species can be explored with major emphasis on these potential areas. However, climate change can result in changes in species ecology [81]; therefore, the boundaries of existing AERs have to be redefined according to future climate changes. Accordingly, suitable areas in re-defined AERs will have to be computed and those changes should be considered in future applications.

NUFS have become popular and high in demand in Sri Lanka due to the increased popularity of their medicinal properties. Generally, these plants are not commonly cultivated in Sri Lanka and are mainly harvested from home gardens and the wild. The production of these NUFS in Sri Lanka has been in decline due to the fragmentation of habitats for development projects and the impacts of climate change. Per-capita consumption of fruits in Sri Lanka is still well below the recommended level of the daily average of $40 \mathrm{~g}$ [6]. Micronutrient deficiencies have also become a growing health problem [82]. Under these circumstances, NUFS can be a very good substitute for combating "hidden hunger" and the most cost-effective means of alleviating vitamins, minerals and other micronutrient deficiencies. NUFS are generally seasonal fruits and the production and quality of NUFS is directly affected by changing climatic conditions. Therefore, identification of climatically suitable areas is important to promote the cultivation of NUFS. This is important to assure a smooth and continuous supply of NUFS to the market as demand increases.

Modeling studies have shown that the potential area of suitability for NUFS will decrease in the future, especially in developing countries [83]. Our results corroborate these findings and reaffirm that climate change will result in substantial losses to the future survival of NUFS, food security and well-being. Meanwhile, agro-climatologists propose introducing NUFS as an alternative to staple crops considering their resilience and natural adaptation to adverse climatic conditions [84]. Modeling studies are intended to provide critical spatial and temporal data as well as information that helps scientific decision-making and produces policy and regulatory frameworks and smart-solutions to promote commercial cultivation and the sustainable utilization of NUFS across the country. However, limited studies have been undertaken globally to identify the potential ranges of NUFS under climate change [8]. Though there are uncertainties, SDM is widely acknowledged as the best applicable technique for predicting the potential distribution of species [85]. Hitherto, no comprehensive study has been carried out, although there is very good potential to utilize SDM for the strategic management of NUFS in Sri Lanka.

Results of this analysis encourage developing climate change adaptation strategies to reduce the vulnerability of NUFS to climate change and sustain their cultivation in growing areas. We suggest developing species-specific strategies to improve the resilience of NUFS to climate change as species response to climate change can differ [85]. Local scientists and policymakers will have to be vigilant about the future climate change impacts and evaluate the genetic resources in genebanks and in the wild for the introduction of improved climate-resistant NUFS varieties. Policymakers and decision-makers should identify the crucial role that NUFS can play as an important source of global food and nutrition security, and take appropriate actions to promote and cultivate NUFS in climatically suitable areas.

\section{Conclusions}

Using Sri Lanka as a case study, we have shown the impacts of projected climate change on NUFS distribution in a tropical climate. The findings of the present study suggest that climate change particularly increases the vulnerability of NUFS and shrinks their potentially suitable areas significantly. Evidently, this can result in serious implications for future food security, human nutrition and well-being. Our results also support the general understanding that tropical species would shift to cooler areas in high altitudes under climate change. T. indica is predicted to be at the greatest risk and 
thus immediate conservation and management actions are needed. Our findings also indicate that dry and intermediate zones will suffer the highest suitable area losses from projected climate changes. Therefore, we highlight the requirements of climate change mitigation and adaption strategies with a clear focus on the targeted areas, which should be well-communicated among researchers, policymakers and decision-makers. Further, researchers should be encouraged to develop climate-resilient NUFS varieties in order to adapt to adverse climate challenges in vulnerable areas.

Supplementary Materials: The following are available online at http://www.mdpi.com/2073-4395/10/1/34/s1, Figure S1: Agro-ecological regions of Sri Lanka; Figure S2. Results of multicolinearity analysis of 19 bioclimatic variables; Figure S3: Results of Jackknife of regularized training gain for selected priority NUFS, Aegle marmelos (a), Annona muricata (b), Limonia acidissima (c) and Tamarindus indica (d) in Sri Lanka; Figure S4: Potentially suitable area of prediction above the selected threshold (maximum training sensitivity plus specificity) of selected priority NUFS, Limonia acidissima, Aegle marmelos, Annona muricata and Tamarindus indica in Sri Lanka under medium-emissions (RCP 4.5) and high-emissions (RCP 8.5) scenarios for 2050 and 2070; Figure S5: District map of Sri Lanka; Table S1: Prioritization of NUFS; Table S2: Details of NUFS occurrences used in the study; Table S3: Evaluation of model performances of NUFS, Aegle marmelos, Annona muricata, Limonia acidissima, Tamarindus indica and Phyllanthus emblica in Sri Lanka; Table S4: Projected suitable area of prediction and percentage area change of the selected priority NUFS under medium-emissions (RCP 4.5) and high-emissions (RCP 8.5) scenarios for 2050 and 2070.; Table S5: Agro-ecological regions (AERs) potentially suitable for selected priority NUFS in Sri Lanka under medium-emissions (RCP 4.5) and high-emissions (RCP 8.5) scenarios for 2050 and 2070.

Author Contributions: Conceptualization, S.S.R.; L.K. and C.S.K.; methodology, S.S.R.; L.K. and C.S.K.; software, S.S.R. and C.S.K.; formal analysis, S.S.R. and C.S.K.; writing-original draft preparation, S.S.R.; writing一review and editing, S.S.R.; L.K. and C.S.K.; supervision, L.K. All authors have read and agreed to the published version of the manuscript.

Funding: This research received no external funding.

Acknowledgments: We would like to thank H.K. Kadupitiya for providing the climate data used in this study. We are also grateful to the Global Environment Facility (GEF)-funded projects "In-situ conservation of crop wild relatives through enhanced Information management and field application" (2004-2010), "Mainstreaming biodiversity conservation and sustainable use for improved human nutrition and well-being" (2011-2018) and "Mainstreaming agrobiodiversity conservation and use in Sri Lankan agro-ecosystems for livelihoods and adaptation to climate change" (2011-2018), implemented by the Department of Agriculture and Ministry of Environment and SL-USA Cooperative germplasm development project on underutilized fruit species for exploration, collection, conservation and characterization of underutilized fruits 2003-2008, implemented by the Department of Agriculture, for providing geo-referenced occurrence data of studied species.

Conflicts of Interest: The authors declare no conflict of interest.

\section{References}

1. Galhena, D.H.; Freed, R.; Maredia, K.M. Home gardens: A promising approach to enhance household food security and wellbeing. Agric. Food Secur. 2013, 2, 8. [CrossRef]

2. MoFE. Biodiversity Conservation in Sri Lanka: A Framework for Action; Ministry of Forestry and Environment: Battaramulla, Sri Lanka, 1999.

3. MoMD\&E. National Biodiversity Strategic Action Plan 2016-2022. Colombo, Sri Lanka; Ministry of Mahaweli Development and Environment: Colombo, Sri Lanka, 2016.

4. Punyawardena, B.V.R. Rainfall of Sri Lanka and Agroecological Zones; Department of Agriculture: Peradeniaya, Sri Lanka, 2008.

5. Pushpakumara, G.; Silva, P. Agrobiodiverisity in Sri Lanka; Biodiversity Secretariat, Ministry of Environment and Natural Resources: Battaramulla, Sri Lanka, 2009.

6. Dahanayake, N. Some neglected and underutilized fruit-crops in Sri Lanka. Int. J. Sci. Res. Publ. 2015, 5, 1-7.

7. Haq, N. Fruits for the Future in Asia. In Proceedings of a Regional Consultation Meeting on Utilization of Tropical Fruit Trees in Asia; Crops for the Future: Bangkok, Thailand, 2002.

8. Padulosi, S.; Heywood, V.; Hunter, D.; Jarvis, A. Underutilized species and climate change: Current status and outlook. In Crop Adaptation to Climate Change; Yadav, S.S., Redden, R.J., Hatfield, J.L., Eds.; Blackwell Publishing Ltd.: Oxford, UK, 2011; pp. 507-521.

9. Padulosi, S.; Hodgkin, T.; Williams, J.; Haq, N. 30 Underutilized crops: Trends, challenges and opportunities in the 21st century. In Managing Plant Genetic Diversity; Engels, J.M.M., Ramanatha Rao, V., Brown, A.H.D., Jackson, M.T., Eds.; CAB International Publishing: Wallingford, UK, 2002; pp. 323-338. 
10. Delêtre, M.; Gaisberger, H.; Arnaud, E. Agrobiodiversity in Perspectives—A Review of Questions, Tools, Concepts and Methodologies; Bioversity International: Rome, Italy, 2012; p. 77.

11. Mabhaudhi, T.; Chimonyo, V.G.P.; Hlahla, S.; Massawe, F.; Mayes, S.; Nhamo, L.; Modi, A.T. Prospects of orphan crops in climate change. Planta 2019, 250, 695-708. [CrossRef] [PubMed]

12. Gruber, K. Agrobiodiversity: The living library. Nature 2017, 544, S8-S10. [CrossRef] [PubMed]

13. Padulosi, S.; Thompson, J.; Rudebjer, P. Fighting Poverty, Hunger and Malnutrition with Neglected and Underutilized Species: Needs, Challenges and the Way Forward; Bioversity International: Rome, Italy, 2013.

14. Pushpakumara, D.K.N.G.; Gunasena, H.P.M.; Singh, V.P. Underutilized Fruit Trees in Sri Lanka Volume 1; World Agroforestry Centre, South Asia Office: New Delhi, India; National Multipurpose Tree Species Research Network of Sri Lanka; Sri Lanka Council for Agriculture Research Policy; Asian Centre for Underutilized Crops in Sri Lanka: New Delhi, India, 2007.

15. Castañeda-Álvarez, N.P.; Khoury, C.K.; Achicanoy, H.A.; Bernau, V.; Dempewolf, H.; Eastwood, R.J.; Guarino, L.; Harker, R.H.; Jarvis, A.; Maxted, N. Global conservation priorities for crop wild relatives. Nat. Plants 2016, 2, 16022. [CrossRef]

16. Chivenge, P.; Mabhaudhi, T.; Modi, A.; Mafongoya, P. The potential role of neglected and underutilised crop species as future crops under water scarce conditions in Sub-Saharan Africa. In. J. Environ. Res. Public Health 2015, 12, 5685-5711. [CrossRef]

17. Bandula, A.; Jayaweera, C.; De Silva, A.; Oreiley, P.; Karunarathne, A.; Malkanthi, S. Role of underutilized crop value chains in rural food and income security in Sri Lanka. Procedia Food Sci. 2016, 6, 267-270. [CrossRef]

18. Li, X.; Siddique, K.H.M. Future Smart Food-Rediscovering Hidden Treasures of Neglected and Underutilized Species for Zero Hunger in Asia; Food \& Agriculture Organisation of the United Nations Bangkok: Bangkok, Thailand, 2018; pp. 51-59.

19. Malkanthi, S. Importance of Underutilized Crops in Thanamalwila Divisional Secretariat Division in Monaragala District in Sri Lanka. J. Agric. Sci. Sri Lanka 2017, 12. [CrossRef]

20. Singh, A.; Dubey, P.K.; Chaurasia, R.; Dubey, R.K.; Pandey, K.K.; Singh, G.S.; Abhilash, P.C. Domesticating the Undomesticated for Global Food and Nutritional Security: Four Steps. Agronomy 2019, 9, 491. [CrossRef]

21. Brijesh, S.; Daswani, P.; Tetali, P.; Antia, N.; Birdi, T. Studies on the antidiarrhoeal activity of Aegle marmelos unripe fruit: Validating its traditional usage. BMC Complement. Altern. Med. 2009, 9, 47. [CrossRef]

22. El-Siddig, K.; Gunasena, H.P.M.; Prasad, B.A.; Pushpakumara, D.K.N.G.; Ramana, K.V.R.; Vijayanand, P.; Williams, J.T. Tamarind: Tamarindus Indica. Vol. 1; Southampton Centre for Underutilised Crops: Southampton, UK, 2006.

23. Pareek, O.P.; Sharma, S. Underutilized Fruits and Nuts Vol.2; Aavishkar Publishers Distributors: Jaipur, India, 2009.

24. Ilaiyaraja, N.; Likhith, K.; Babu, G.S.; Khanum, F. Optimisation of extraction of bioactive compounds from Feronia limonia (wood apple) fruit using response surface methodology (RSM). Food Chem. 2015, 173, 348-354. [CrossRef] [PubMed]

25. Jama, B.; Mohamed, A.; Mulatya, J.; Njui, A. Comparing the "Big Five": A framework for the sustainable management of indigenous fruit trees in the drylands of East and Central Africa. Ecol. Indic. 2008, 8, 170-179. [CrossRef]

26. Moghadamtousi, S.; Fadaeinasab, M.; Nikzad, S.; Mohan, G.; Ali, H.; Kadir, H. Annona muricata (Annonaceae): A review of its traditional uses, isolated acetogenins and biological activities. Int. J. Mol. Sci. 2015, 16, 15625-15658. [CrossRef] [PubMed]

27. Kuru, P. Tamarindus indica and its health related effects. Asian Pac. J. Trop. Biomed. 2014, 4, 676-681. [CrossRef]

28. Pradhan, D.; Tripathy, G.; Patanaik, S. Anticancer activity of Limonia acidissima Linn (Rutaceae) fruit extracts on human breast cancer cell lines. Trop. J. Pharm. Res. 2012, 11, 413-419. [CrossRef]

29. Ilango, K.; Chitra, V. Wound healing and anti-oxidant activities of the fruit pulp of Limonia acidissima Linn (Rutaceae) in rats. Trop. J. Pharm. Res. 2010, 9, 223-230. [CrossRef]

30. Rahman, S.; Parvin, R. Therapeutic potential of Aegle marmelos (L.)-An overview. Asian Pac. J. Trop. Dis. 2014, 4, 71-77. [CrossRef] 
31. Adewole, S.O.; Caxton-Martins, E.A. Morphological changes and hypoglycemic effects of Annona muricata linn.(annonaceae) leaf aqueous extract on pancreatic $\beta$-cells of streptozotocin-treated diabetic rats. Afr. J. Biomed. Res. 2006, 9. [CrossRef]

32. Liu, N.; Yang, H.L.; Wang, P.; Lu, Y.C.; Yang, Y.J.; Wang, L.; Lee, S.C. Functional proteomic analysis revels that the ethanol extract of Annona muricata L. induces liver cancer cell apoptosis through endoplasmic reticulum stress pathway. J. Ethnopharmacol. 2016, 189, 210-217. [CrossRef]

33. Havinga, R.M.; Hartl, A.; Putscher, J.; Prehsler, S.; Buchmann, C.; Vogl, C.R. Tamarindus indica L.(Fabaceae): Patterns of use in traditional African medicine. J. Ethnopharmacol. 2010, 127, 573-588. [CrossRef]

34. MoE. Sri Lanka's Second National Communication on Climate Change; Ministry of Environment: Colombo, Sri Lanka, 2011.

35. Jayawardena, S.; Dharshika, T.; Herath, R. Observed climate trends, future climate change projections and posible impacts for Sri Lanka. 'Neela Haritha' Clim. Chang. Mag. Sri Lanka 2017, 2, 144-151.

36. Eckstein, D.; Hutfils, M.; Winges, M. Global Climate Risk Index 2019_Who Suffers Most From Extreme Weather Events? Weather-Related Loss Events in 2017 and 1998 to 2017; Germanwatch: Bonn, Germany, 2018.

37. Potts, S.G.; Biesmeijer, J.C.; Kremen, C.; Neumann, P.; Schweiger, O.; Kunin, W.E. Global pollinator declines: Trends, impacts and drivers. Trends Ecol. Evol. 2010, 25, 345-353. [CrossRef] [PubMed]

38. Williams, J.T.; Haq, N. Global Research on Underutilised Crops; an Assessment of Current Activities and Proposals for Enhanced Cooperation; ICUC: Southampton, UK, 2002.

39. Jayasinghe-Mudalige, U.K.; Henson, S. Economic incentives for firms to implement enhanced food safety controls: Case of the Canadian red meat and poultry processing sector. Rev. Agric. Econ. 2006, 28, 494-514. [CrossRef]

40. Boria, R.A.; Olson, L.E.; Goodman, S.M.; Anderson, R.P. Spatial filtering to reduce sampling bias can improve the performance of ecological niche models. Ecol. Model. 2014, 275, 73-77. [CrossRef]

41. Phillips, S.J.; Dudík, M.; Elith, J.; Graham, C.H.; Lehmann, A.; Leathwick, J.; Ferrier, S. Sample selection bias and presence-only distribution models: Implications for background and pseudo-absence data. Ecol. Appl. 2009, 19, 181-197. [CrossRef]

42. Young, N.; Carter, L.; Evangelista, P.A. MaxEnt Model v3. 3.3 e Tutorial (ArcGIS v10). 2011. Available online: http://ibis.colostate.edu/webcontent/ws/coloradoview/tutorialsdownloads/a_maxent_model_v7.pdf (accessed on 10 March 2019).

43. Hijmans, R.J.; Cameron, S.E.; Parra, J.L.; Jones, P.G.; Jarvis, A. Very high resolution interpolated climate surfaces for global land areas. Int. J. Clim. 2005, 25, 1965-1978. [CrossRef]

44. Watanabe, M.; Suzuki, T.; O’ishi, R.; Komuro, Y.; Watanabe, S.; Emori, S.; Takemura, T.; Chikira, M.; Ogura, T.; Sekiguchi, M. Improved climate simulation by MIROC5: Mean states, variability, and climate sensitivity. J. Clim. 2010, 23, 6312-6335. [CrossRef]

45. Sharmila, S.; Joseph, S.; Sahai, A.; Abhilash, S.; Chattopadhyay, R. Future projection of Indian summer monsoon variability under climate change scenario: An assessment from CMIP5 climate models. Glob. Planet. Chang. 2015, 124, 62-78. [CrossRef]

46. Mishra, V.; Kumar, D.; Ganguly, A.R.; Sanjay, J.; Mujumdar, M.; Krishnan, R.; Shah, R.D. Reliability of regional and global climate models to simulate precipitation extremes over India. J. Geophys. Res. Atmos. 2014, 119, 9301-9323. [CrossRef]

47. Sperber, K.R.; Annamalai, H.; Kang, I.-S.; Kitoh, A.; Moise, A.; Turner, A.; Wang, B.; Zhou, T. The Asian summer monsoon: An intercomparison of CMIP5 vs. CMIP3 simulations of the late 20th century. Clim. Dyn. 2013, 41, 2711-2744. [CrossRef]

48. Kariyawasam, C.S.; Kumar, L.; Ratnayake, R.S.S. Invasive Plant Species Establishment and Range Dynamics in Sri Lanka under Climate Change. Entropy 2019, 21, 571. [CrossRef]

49. Lamsal, P.; Kumar, L.; Aryal, A.; Atreya, K. Invasive alien plant species dynamics in the Himalayan region under climate change. Ambio 2018, 47,697-710. [CrossRef] [PubMed]

50. Su, J.; Aryal, A.; Nan, Z.; Ji, W. Climate change-induced range expansion of a subterranean rodent: Implications for rangeland management in Qinghai-Tibetan Plateau. PLoS ONE 2015, 10, e0138969. [CrossRef] [PubMed]

51. Aryal, A.; Shrestha, U.B.; Ji, W.; Ale, S.B.; Shrestha, S.; Ingty, T.; Maraseni, T.; Cockfield, G.; Raubenheimer, D. Predicting the distributions of predator (snow leopard) and prey (blue sheep) under climate change in the Himalaya. Ecol. Evol. 2016, 6, 4065-4075. [CrossRef] [PubMed] 
52. Leroy, B.; Delsol, R.; Hugueny, B.; Meynard, C.N.; Barhoumi, C.; Barbet-Massin, M.; Bellard, C. Without quality presence-absence data, discrimination metrics such as TSS can be misleading measures of model performance. J. Biogeogr. 2018, 45, 1994-2002. [CrossRef]

53. Boubli, J.; De Lima, M. Modeling the geographical distribution and fundamental niches of Cacajao spp. and Chiropotes israelita in Northwestern Amazonia via a maximum entropy algorithm. Int. J. Primatol. 2009, 30, 217-228. [CrossRef]

54. Ibanez, I.; Silander, J., Jr.; Allen, J.M.; Treanor, S.A.; Wilson, A. Identifying hotspots for plant invasions and forecasting focal points of further spread. J. Appl. Ecol. 2009, 46, 1219-1228. [CrossRef]

55. O'donnell, J.; Gallagher, R.V.; Wilson, P.D.; Downey, P.O.; Hughes, L.; Leishman, M.R. Invasion hotspots for non-native plants in Australia under current and future climates. Glob. Chang. Biol. 2012, 18, 617-629. [CrossRef]

56. Beaumont, L.J.; Hughes, L.; Poulsen, M. Predicting species distributions: Use of climatic parameters in BIOCLIM and its impact on predictions of species' current and future distributions. Ecol. Model. 2005, 186, 251-270. [CrossRef]

57. Elith, J. Predicting Distributions of Invasive Species 2015. Available online: https://arxiv.org/ftp/arxiv/papers/ 1312/1312.0851.pdf (accessed on 12 February 2019).

58. Mod, H.K.; Scherrer, D.; Luoto, M.; Guisan, A. What we use is not what we know: Environmental predictors in plant distribution models. J. Veg. Sci. 2016, 27, 1308-1322. [CrossRef]

59. Heumann, B.W.; Walsh, S.J.; Verdery, A.M.; McDaniel, P.M.; Rindfuss, R.R. Land suitability modeling using a geographic socio-environmental niche-based approach: A case study from northeastern Thailand. Ann. Assoc. Am. Geogr. 2013, 103, 764-784. [CrossRef] [PubMed]

60. Kadupitiya, H.K.; De Silva, S.H.S.A.; Dilshani, D.G.S.; Weerasinghe, P. Distribution of soil organic carbon in Sri Lanka: A GIS based modeling approach. Trop. Agric. 2018, 166, 91-106.

61. Phillips, S.J.; Anderson, R.P.; Dudík, M.; Schapire, R.E.; Blair, M.E. Opening the black box: An open-source release of Maxent. Ecography 2017, 40, 887-893. [CrossRef]

62. Phillips, S.; Anderson, R.P.; Schapire, R.E. Maximum entropy modelling of species geographic distributions. Ecol. Model. 2006, 190, 231-259. [CrossRef]

63. Wisz, M.S.; Hijmans, R.J.; Li, J.; Peterson, A.T.; Graham, C.; Guisan, A.; Group, N.P.S.D.W. Effects of sample size on the performance of species distribution models. Divers. Distrib. 2008, 14, 763-773. [CrossRef]

64. Phillips, S.J.; Dudík, M.; Schapire, R.E. A maximum entropy approach to species distribution modeling. In Proceedings of the Twenty-First International Conference on Machine Learning (ACM), Banff, AB, Canada, 4-8 July 2004; p. 83.

65. Hernandez, P.A.; Graham, C.H.; Master, L.L.; Albert, D.L. The effect of sample size and species characteristics on performance of different species distribution modeling methods. Ecography 2006, 29, 773-785. [CrossRef]

66. Elith, J.; Phillips, S.J.; Hastie, T.; Dudík, M.; Chee, Y.E.; Yates, C.J. A statistical explanation of MaxEnt for ecologists. Divers. Distrib. 2011, 17, 43-57. [CrossRef]

67. Merow, C.; Smith, M.J.; Silander, J.A. A practical guide to MaxEnt for modeling species' distributions: What it does, and why inputs and settings matter. Ecography 2013, 36, 1058-1069. [CrossRef]

68. Baldwin, R. Use of maximum entropy modeling in wildlife research. Entropy 2009, 11, 854-866. [CrossRef]

69. Graham, C.H.; Elith, J.; Hijmans, R.J.; Guisan, A.; Townsend Peterson, A.; Loiselle, B.A.; Group, N.P.S.D.W. The influence of spatial errors in species occurrence data used in distribution models. J. Appl. Ecol. 2008, 45, 239-247. [CrossRef]

70. Phillips, S.J. Transferability, sample selection bias and background data in presence-only modelling: A response to Peterson et al.(2007). Ecography 2008, 31, 272-278. [CrossRef]

71. Phillips, S.J.; Dudík, M. Modeling of species distributions with Maxent: New extensions and a comprehensive evaluation. Ecography 2008, 31, 161-175. [CrossRef]

72. Phillips, S.J. A Brief Tutorial on Maxent 2017. Available online: http://biodiversityinformatics.amnh.org/ open_source/maxent/ (accessed on 20 February 2019).

73. Cheng, A.; Mayes, S.; Dalle, G.; Demissew, S.; Massawe, F. Diversifying crops for food and nutrition security-A case of teff. Biol. Rev. 2017, 92, 188-198. [CrossRef] [PubMed]

74. Allouche, O.; Tsoar, A.; Kadmon, R. Assessing the accuracy of species distribution models: Prevalence, kappa and the true skill statistic (TSS). J. Appl. Ecol. 2006, 43, 1223-1232. [CrossRef]

75. Swets, J.A. Measuring the accuracy of diagnostic systems. Science 1988, 240, 1285-1293. [CrossRef] 
76. Peterson, A.T.; Soberón, J.; Pearson, R.G.; Anderson, R.P.; Martínez-Meyer, E.; Nakamura, M.; Araújo, M.B. Ecological Niches and Geographic Distributions (MPB-49); Princeton University Press: Princeton, NJ, USA, 2011.

77. Pramanik, M.; Paudel, U.; Mondal, B.; Chakraborti, S.; Deb, P. Predicting climate change impacts on the distribution of the threatened Garcinia indica in the Western Ghats, India. Clim. Risk Manag. 2018, 19, 94-105. [CrossRef]

78. Liu, C.; Newell, G.; White, M. On the selection of thresholds for predicting species occurrence with presence-only data. Ecol. Evol. 2016, 6, 337-348. [CrossRef]

79. Pinto, A.C.Q.; Cordeiro, M.C.R.; Andrade, S.R.M.; Ferreira, F.R.; Filgueiras, H.A.C.; Alves, R.E.; Kinpara, D.I. Annona Species; International Centre for Underutilised Crops: Southampton, UK, 2005; p. 261.

80. Orwa, C.; Mutua, A.; Kindt, R.; Jamnadass, R.; Anthony, S. Agroforestree Database: A Tree Reference and Selection Guide Version 4.0; World Agroforestry Centre: Nairobi, Kenya, 2009.

81. Walther, G.-R.; Post, E.; Convey, P.; Menzel, A.; Parmesan, C.; Beebee, T.J.; Fromentin, J.-M.; Hoegh-Guldberg, O.; Bairlein, F. Ecological responses to recent climate change. Nature 2002, 416, 389-395. [CrossRef]

82. Weerahewa, J.; Rajapakse, C.; Pushpakumara, G. An analysis of consumer demand for fruits in Sri Lanka. 1981-2010. Appetite 2013, 60, 252-258. [CrossRef]

83. Abel, C.; Dumisani, K.; Precious, M.; Upenyu, N.D.R. Assessing the impact of climate change on the suitability of rainfed flu-cured tobacco (Nicotiana tobacum) production in Zimbabwe. In Proceedings of the 1st Climate Science Symposium of Zimbabwe, Cresta Lodge, Harare, Zimbabwe, 19-21 June 2013.

84. Rao, N.; Shahid, M.; Al Shankiti, A.; Elouafi, I. Neglected and underutilized species for food and income security in marginal environments. Middle East Hortic. Summit 2013, 1051, 91-103. [CrossRef]

85. Kariyawasam, C.S.; Kumar, L.; Ratnayake, S.S. Invasive Plants Distribution Modeling: A Tool for Tropical Biodiversity Conservation with Special Reference to Sri Lanka. Trop. Conserv. Sci. 2019, 12, 1-12. [CrossRef]

(C) 2019 by the authors. Licensee MDPI, Basel, Switzerland. This article is an open access article distributed under the terms and conditions of the Creative Commons Attribution (CC BY) license (http://creativecommons.org/licenses/by/4.0/). 